\title{
Gastric pneumatosis in a preterm infant following initial empiric antibiotic therapy
}

\author{
Mohammad A A Bayoumi 두, Einas Elzubier Elmalik
}

Neonatal Intensive Care Unit (NICU), Women's Wellness and Research Center (WWRC), Hamad Medical Corporation, Doha, Qatar

\section{Correspondence to}

Dr Mohammad A A Bayoumi; moh.abdelwahab@hotmail.com

Accepted 7 October 2021
Check for updates

(C) BMJ Publishing Group Limited 2021. No commercial re-use. See rights and permissions. Published by BMJ.

To cite: Bayoumi MAA,
Elmalik EE. BMJ Case
Rep 2021;14:e246446.
doi:10.1136/bcr-2021-
246446

\section{DESCRIPTION}

The case is of a twin A male infant born preterm vaginally at 31 weeks as a product of dichorionic diamniotic twins gestation. The mother was 23 years old, gravida 3 para 0 , with gestational diabetes on a diet regimen. She did not have any risk factors for infection. She was seen in the antenatal clinic 5 weeks before the onset of labour with no maternal or fetal concerns. Her twins were growing normally with no congenital anomalies seen in the antenatal ultrasound scans. On the delivery day, she arrived at the emergency room fully dilated with premature rupture of membranes (PROM) at the onset of labour. She did not receive any antenatal steroids before the delivery.

The infant was born in a good condition with an Apgar score of 9 and 10 at 1 and 5 min, respectively. He was admitted to the neonatal intensive care unit (NICU) together with his twin due to prematurity and respiratory distress syndrome. Regarding his respiratory support, he was supported by nasal continuous positive airway pressure (NCPAP) since birth for 11 hours and by nasal cannula for another 2 days. The treating team started empiric initial antibiotic therapy at birth by ampicillin and amikacin based on the preterm labour and the PROM. The antibiotic therapy was continued for 5 days despite the sterile blood culture at 48 hours of age and repeatedly negative C-reactive protein (CRP).

The other twin $B$ received ampicillin and amikacin at birth and it was stopped after 2 days due to negative cultures. He was supported by NCPAP for 12 hours and by nasal cannula for 13 days. He had a smooth NICU course with no complications.

On the fifth day of life, this infant (twin A) was noted to have poor activity, lethargy with frequent attacks of bradycardia and desaturation. Based on the clinical presentation, the neonatal team considered late-onset sepsis and necrotising enterocolitis (NEC) as possible initial differential diagnoses.

Complete blood count (CBC) and peripheral smear were of normal values and blood culture was negative at that time. CRP was elevated to $49 \mathrm{mg} / \mathrm{L}$. Capillary blood gases showed partially compensated metabolic acidosis while the coagulation profile and serum electrolytes were normal. Anteroposterior (figure 1) and cross table (figure 2) abdominal X-ray was done and showed pneumatosis intestinalis, portal venous gas and gastric pneumatosis with no free air. Ultrasound of the abdomen showed scanty free ascites with tiny bright

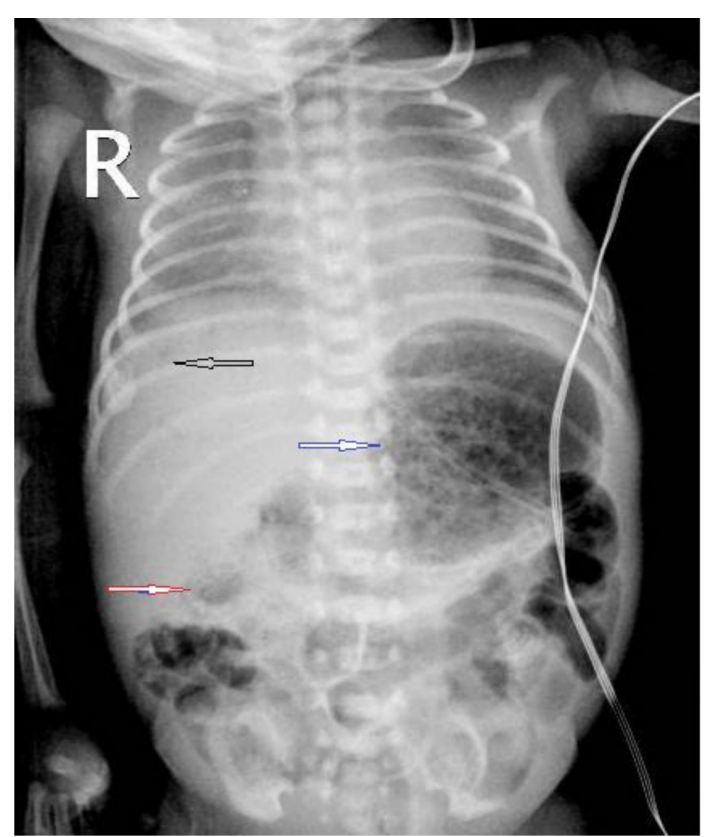

Figure 1 Antero-posterior X-ray of the abdomen shows gastric pneumatosis (blue arrow), pneumatosis intestinalis (red arrow) and air in the portal tract (black arrow).

foci within hepatic parenchyma, indicating portal tract air foci (figure 3).

The infant was supported by NCPAP for few hours which was escalated to conventional mechanical ventilation for 2 days before extubation to a nasal cannula for another 2 days. The paediatric surgery team was consulted and the infant was kept nil per mouth for 14 days. A peripherally inserted central catheter was placed and the infant received intravenous teicoplanin, intravenous amikacin and intravenous metronidazole for 14 days.

Late-onset sepsis was excluded based on the negative blood culture and normal CBC parameters. As a final diagnostic aetiology, the neonatal

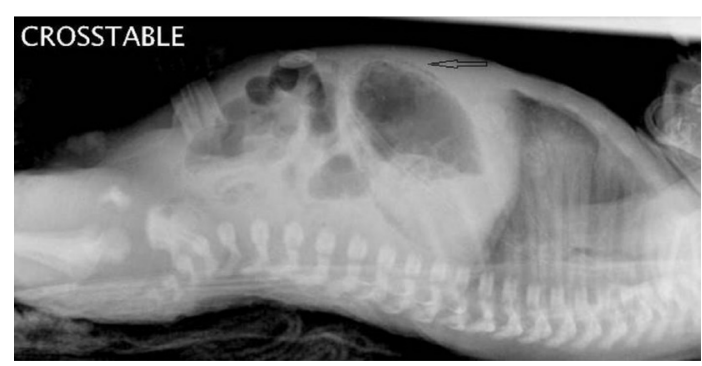

Figure 2 Cross table X-ray of the abdomen shows gastric pneumatosis. 


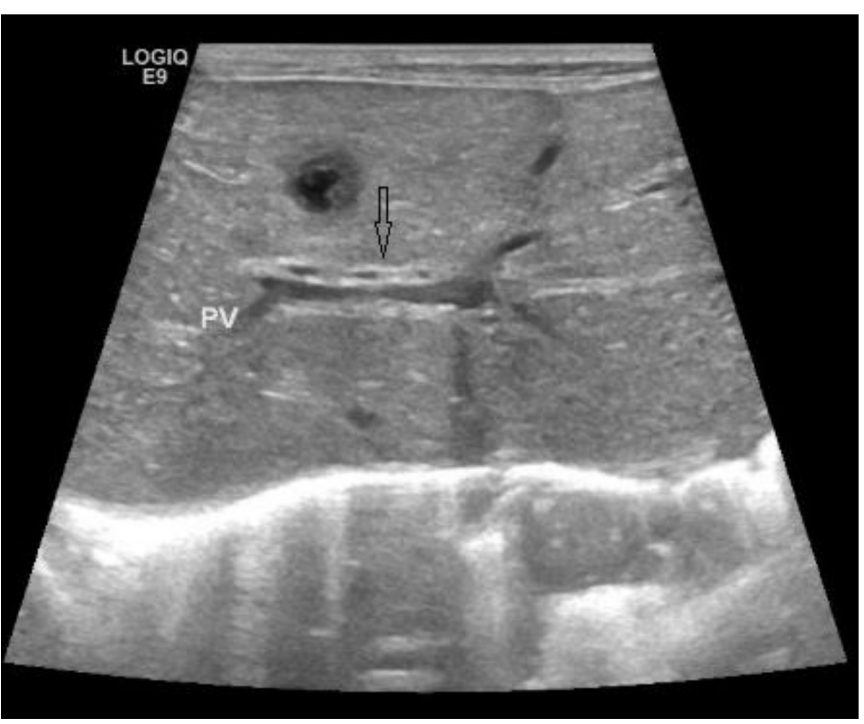

Figure 3 Ultrasound of the abdomen shows air in the portal vein (PV).

team labelled this patient as a grade II B NEC based on Bells's staging criteria. ${ }^{1}$

Close follow-up showed gradual clinical and radiological improvement which started 2 days after the initiation of therapy till complete recovery. The infant was discharged home safely on the 35 th day of life after achieving full oral feeding with steady weight gain.

The absence of NEC symptoms and signs in twin B that was seen in twin A can be explained by the shorter duration of the antibiotic therapy which is 2 days only in the healthy twin.

Gastric pneumatosis is a rare presentation of NEC in the first week of life. It develops as a result of altered gut microbiota following empiric initial antibiotic administration for preterm infants leading to overgrowth of pathologic virulent organisms over the commensals. $^{2-5}$

Other causes of gastric pneumatosis include isolated gastric pneumatosis, sepsis, gastritis, congenital hypertrophic pyloric stenosis, displaced gastric tubes, following steroid and cyclooxygenase inhibitor (COX-inhibitor), for example, Ibuprofen exposure, jejunal atresia and non-invasive positive pressure ventilation, especially in babies with cyanotic congenital heart disease and large patent ductus arteriosus. ${ }^{6-9}$

\section{Learning points}

- Initial empiric use of antibiotics should not be routinely administered for preterm infants on delivery as it is strongly associated with intestinal dysbiosis and increased incidence of NEC.

- The use of early antibiotic therapy for preterm infants after delivery should be restricted to indicated cases with risk factors of early-onset sepsis. It should be stopped as soon as the cultures and the rest of the sepsis workup is negative.

Contributors MAAB has written the manuscript and collected the images. EEE has intellectually revised the manuscript.

Funding The authors have not declared a specific grant for this research from any funding agency in the public, commercial or not-for-profit sectors.

Competing interests None declared.

Patient consent for publication Consent obtained from next of kin.

Provenance and peer review Not commissioned; externally peer reviewed.

\section{ORCID iDs}

Mohammad A A Bayoumi http://orcid.org/0000-0002-2627-4806

Einas Elzubier Elmalik http://orcid.org/0000-0003-2518-8161

\section{REFERENCES}

1 Kliegman RM, Walsh MC. Neonatal necrotizing enterocolitis: pathogenesis, classification, and spectrum of illness. Curr Probl Pediatr 1987;17:219-88.

2 Raba AA, O'Sullivan A, Miletin J. Pathogenesis of necrotising enterocolitis: the impact of the altered gut microbiota and antibiotic exposure in preterm infants. Acta Paediatr 2021;110:433-40

3 Esmaeilizand R, Shah PS, Seshia M, et al. Antibiotic exposure and development of necrotizing enterocolitis in very preterm neonates. Paediatr Child Health 2018;23:e56-61.

4 Raba AA, O'Sullivan A, Semberova J, et al. Are antibiotics a risk factor for the development of necrotizing enterocolitis-case-control retrospective study. Eur J Pediatr 2019:178:923-8.

5 Underwood MA, Mukhopadhyay S, Lakshminrusimha S, et al. Neonatal intestinal dysbiosis. J Perinatol 2020;40:1597-608.

6 Abusalah ZG, George J. Preterm baby with gastric pneumatosis: a new association with a desirable outcome. BMJ Case Rep 2019;12. doi:10.1136/bcr-2019-230188. [Epub ahead of print: 06 May 2019].

7 Chesley P, Stark R, McAdams R, et al. Isolated gastric pneumatosis in a premature infant following steroid exposure. J Pediatr Surg Case Rep 2014;2:436-8.

8 Chew SJ, Victor RS, Gopagondanahalli KR, et al. Pneumatosis intestinalis in a preterm infant: should we treat all intestinal pneumatosis as necrotising enterocolitis? BMJ Case Rep 2018;2018. doi:10.1136/bcr-2018-224356. [Epub ahead of print: 28 Mar 2018].

9 Penninga L, Werz MJ, Reurings JC, et al. Gastric pneumatosis in a small-for-gestationalage neonate: Figure 1. BMJ Case Rep 2015;2015:bcr2014208390.

Copyright 2021 BMJ Publishing Group. All rights reserved. For permission to reuse any of this content visit

https://www.bmj.com/company/products-services/rights-and-licensing/permissions/

BMJ Case Report Fellows may re-use this article for personal use and teaching without any further permission.

Become a Fellow of BMJ Case Reports today and you can:

- Submit as many cases as you like

- Enjoy fast sympathetic peer review and rapid publication of accepted articles

- Access all the published articles

- Re-use any of the published material for personal use and teaching without further permission

Customer Service

If you have any further queries about your subscription, please contact our customer services team on +44 (0) 2071111105 or via email at support@bmj.com.

Visit casereports.bmj.com for more articles like this and to become a Fellow 